\title{
Modeling and design of the improved D-STATCOM control for power distribution grid
}

\author{
Kamel Djamel Eddine Kerrouche ${ }^{1,2} \cdot$ Ehtisham Lodhi ${ }^{3,4}$. Mustapha Boualem Kerrouche ${ }^{5}$. Lina Wang ${ }^{1}$. \\ Fenghua $\mathrm{Zhu}^{3,4} \cdot$ Gang Xiong $^{6}$ (D)
}

Received: 5 March 2020 / Accepted: 7 August 2020 / Published online: 15 August 2020

(c) Springer Nature Switzerland AG 2020

\begin{abstract}
The distribution static compensator (D-STATCOM) is a power quality compensator, which can be utilized for improving the power quality of the distribution power grid by managing the flow of reactive power and unbalanced caused by variable and unbalanced loads. This paper develops the concept of regulating the D-STATCOM scheme to improve the dynamic proficiency of the power distribution network during electrical network defects, such as voltage drops and voltage swells. Furthermore, the methodology adopted in this research paper is established to utilize the sliding mode control (SMC) for the proper working of D-STATCOM. The simulation of the suggested SMC methodology has been carried out by employing the MATALB/Simulink software and compared the results with traditional proportional integrator regulator. The results show that the suggested approach controlling the D-STATCOM achieves sinusoidal and symmetrical grid current with less harmonics; moreover, it can efficiently eliminate the oscillations produced in active and reactive power. Hence, the proposed strategy is helpful in mitigating the voltage flicker and improving the overall efficiency of the distribution grid.
\end{abstract}

Keywords Distribution static compensator (D-STATCOM) · Sliding mode control (SMC) · Proportional integrator (PI)

\section{Introduction}

The power quality of the distribution grid has been degraded due to propagation of power electronic devices, variable unbalanced and nonlinear loads. The traditional power devices are most favored to enhance the power quality of the overall system [1, 2]. From the literature, it can be seen that numerous power devices are utilized to lessen the power quality issues by injecting currents-voltages or both into the distribution grid. The D-STATCOM is a shunt connected power equipment that is used to inject current at the point of common couple (PCC) [3].

The development and use of D-FACTS controllers in the distribution power grids have led to many applications that ensure the stability of the global network [4]. In [5], the various synthesizing controllers are utilized to improve the overall efficiency of distribution power grid with stable voltage. One of these issues addressed in other research to advance the dynamic performance of power distribution grid, while improving the modulation techniques that are used in D-STATCOM [6]. However, the strict requirement of

$\triangle$ Gang Xiong, gang.xiong@ia.ac.cn; Kamel Djamel Eddine Kerrouche, kkerrouche@cds.asal.dz; Ehtisham Lodhi, lodhi2018@ia.ac.cn; Mustapha Boualem Kerrouche, mustaphakerrouche88@gmail.com; Lina Wang, wangln@buaa.edu.cn; Fenghua Zhu, fenghua.zhu@ia.ac.cn | 'School of Automation Science and Electrical Engineering, Beihang University, Beijing 100191, China. ${ }^{2}$ Satellites Development Center, Algerian Space Agency, Ibn Rochd USTO, Bir El Djir, Box 4065, Oran, Algeria. ${ }^{3}$ The SKL for Management and Control of Complex Systems Institute of Automation, Chinese Academy of Sciences, Beijing 100190, China. ${ }^{4}$ The School of Artificial Intelligence, University of Chinese Academy of Sciences, Beijing 100049, China. ${ }^{5}$ Electro-Technical Engineering Lab, Faculty of Technology, Tahar Moulay University, Sidon, Algeria. ${ }^{6}$ The Cloud Computing Center, Chinese Academy of Sciences, Dongguan 523808, China. 
the total loss in D-STATCOM prevents the usage of these high-frequency modulation methodologies since latter increases the active losses in the switching part (IGBT) [7]. This control has already been applied in the wind system to control the mechanical and electrical part [8-11]. The optimum direct current vector control strategy is utilized to recover the overall efficiency of the STATCOM in electrical grid [12]. The innovative modulations schemes are hired to improve the working of D-STATCOM [13]. The utilization of energy storage devices like super-capacitors in distribution grid has become the dynamic area of scientific research [14]. Furthermore, the integration and control of an energy storage devices with the D-STATCOM are incorporated to overcome the following issues: power quality improvement, reaction time and reliability of the device [15].

In order to design the efficient D-STATCOM control, various control mechanisms are introduced in the literature $[16,17]$. Among them, model predictive control (MPC) and sliding mode control (SMC) are most widely used control methodologies for improving the overall efficiency of the system. The MPC is designed for linear systems to anticipate the desired control and after that developments are made for nonlinear systems. However, SMC is originally designed for nonlinear systems. In fact, each method has a specific application area where it can give excellent performance. The MPC is a model-based control, but SMC is variable structure-based control such as power converters. The MPC is an optimal controller suitable for constrained systems but SMC main used for uncertain systems, which contains unmodeled behaviors (such as voltage and current sensors or power switches delays). The MPC requires a powerful processor to perform calculations in real time, but SMC has very simple calculations. It can be observed that the choice of controller depends on the type of application (power converters, robotics or aerospace systems) and control specifications as well as the cost of the system [18]. For this reason, in this article, the SMC is chosen for its specific application, i.e., to improve D-STATCOM control for power distribution grid and also provide cost-effective solution for improving the overall efficiency of the power grid.

The equivalent electrical circuit of D-STATCOM is presented in Fig. 1, which is designed by the coupling transformer, power inverter based on power electronic components and DC bus. This paper develops the concept of regulating a D-STATCOM scheme to improve dynamic proficiency of the power distribution network during all types of electrical network defects such as voltage drops and voltage swells. Furthermore, the methodology adopted in this research paper is established to utilize the sliding mode control (SMC) for the proper working of D-STATCOM. The simulation of the proposed SMC methodology

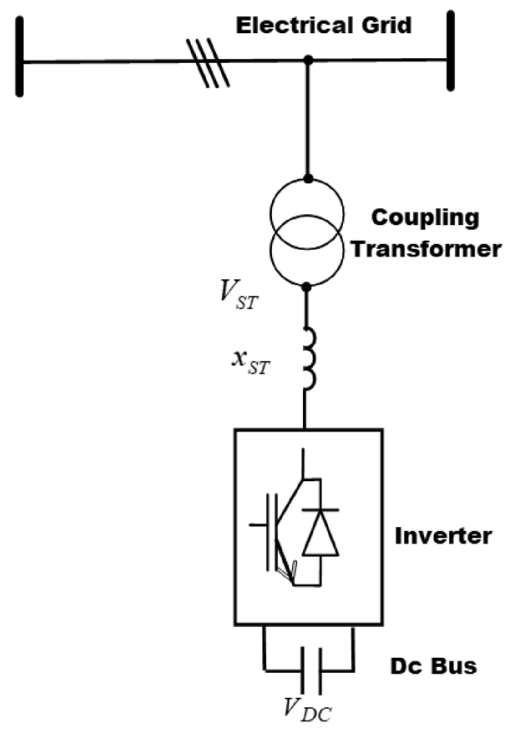

Fig. 1 Simplified equivalent circuit of the D-STATCOM

has been carried out by employing the MATALB/Simulink software and compared the results with traditional PI controller. The simulation results show that proposed control strategy for D-STATCOM not only achieves sinusoidal and symmetrical grid current with less harmonics, in addition efficiently eliminates the oscillation produced in active and reactive power. The suggested approach is helpful in mitigating the voltage flicker and improving the overall efficiency of the distribution grid. Hence, the proposed SMC is developed for the efficient operation of D-STATCOM with good performance to the distribution grid.

\section{The design of D-STATCOM}

In this paper, the main working principle of the D-STATCOM be subject to the control strategy of energy exchange between the converter and the distribution grid, which also depends on the converter's alternative output voltage. This operating principle can be summarized as follows:

- If the amplitude of D-STATCOM output voltage is higher than that of the network, then the current flows through the reactance toward network, the D-STATCOM injects reactive power.

- If the range of output voltage of the converter is less than that of the network, then current flows to the network, the D-STATCOM absorbs reactive power from the network.

- If the range of output voltage of the converter is identical to that of the network, the value of reactive power 
exchange is zero, and the D-STATCOM is in the state of equilibrium.

Equations (1) and (2) are used to describe the powers (active and reactive) injected by D-STATCOM, respectively.

$$
\begin{aligned}
P_{\mathrm{ST}} & =\frac{V_{\mathrm{PCC}} V_{\mathrm{ST}} \sin \delta}{x_{\mathrm{ST}}} \\
Q_{\mathrm{ST}} & =\frac{V_{\mathrm{PCC}}\left(V_{\mathrm{PCC}}-V_{\mathrm{ST}} \cos \delta\right)}{x_{\mathrm{ST}}},
\end{aligned}
$$

where $\delta$ is the angle of shift between voltages $V_{\mathrm{PCC}}$ and $V_{S T}, x_{S T}$ is the reactance of the coupling transformer. In permanent operation, the $V_{2}$ voltage is generated by the D-STATCOM is in tune with voltage $V_{\mathrm{PCC}}(\delta=0)$, so there is only the flow of reactive power $\left(P_{\mathrm{ST}}=0\right)$. From Eq. (2), the amount of reactive power is expressed as:

$Q_{S T}=\frac{V_{\mathrm{PCC}}\left(V_{\mathrm{PCC}}-V_{\mathrm{ST}}\right)}{x_{\mathrm{ST}}}$.

The capacitor plugged into the D-STATCOM continuous bus reacts as a source of continuous tension. In permanent operation, the voltage $V_{S T}$ is shifted late to maintain voltage $V_{\mathrm{PCC}}$ in the constant continuous bus and to compensate for losses in the D-STATCOM switches and in the coupling transformer. Figure 4 displays the correspondent circuit of the D-STATCOM, the resistance signifies the active losses of switches and transformer, while the series inductance characterizes the leakages of coupling transformer.

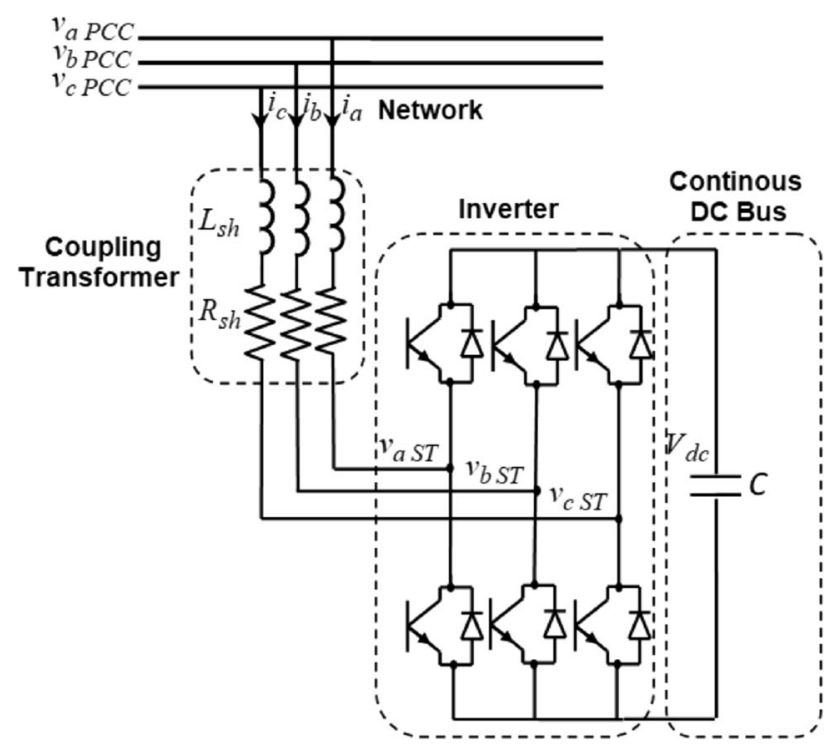

Fig. 2 Simplified equivalent circuit of the D-STATCOM
The two-level inverter shown in Fig. 2 is replaced by three-phase and three-level NPC-type inverter for its advantages. Figure 3 shows the configuration of the threephase and three-level inverter with NPC structure. In the DC bus of the D-STATCOM, a super-capacitor is inserted.

The design of the D-STATCOM is based on three-phase and three-level inverter with NPC structure, which includes two sources of DC voltage and three arms each has a bidirectional switch and two antiparallel diodes $\mathrm{DD}_{\mathrm{k} 0}$ and $\mathrm{DD}_{\mathrm{k} 1}$, allowing to have the zero level of the inverter output voltage. This structure requires the use of controllable switches for priming and blocking. The structure of the N.P.C uses two input voltages: $V C_{1}$ and $V C_{2}$. It consists in creating a midpoint on the voltage value of the $D C$ bus $\left(E=V C_{1}+V C_{2}=V_{d c}\right)$, making it possible to generate slots of amplitude $(-E / 2,0,+E / 2)$, whose combination allows have a signal form closer to the sinusoid than with the classic two-level inverter structure. Moreover, for an input voltage $E$, the switches of a three-level inverter support half the voltage supported by those of a two-level inverter.

The super-capacitor is system that stores energy as potential energy from an electrostatic field, in the same way as ordinary capacitor. The difference is that the super-capacitor has a higher capacity. In addition, the

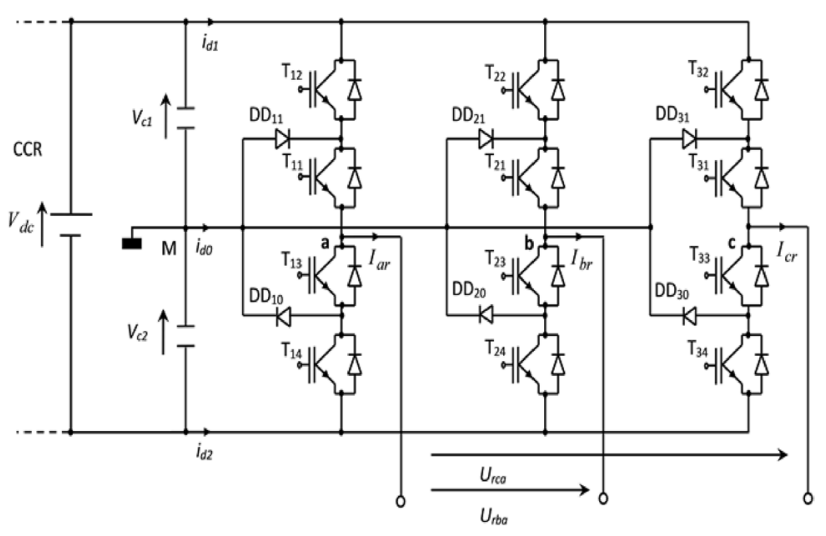

Fig. 3 Structure of a three-phase and three-level NPC-type inverter

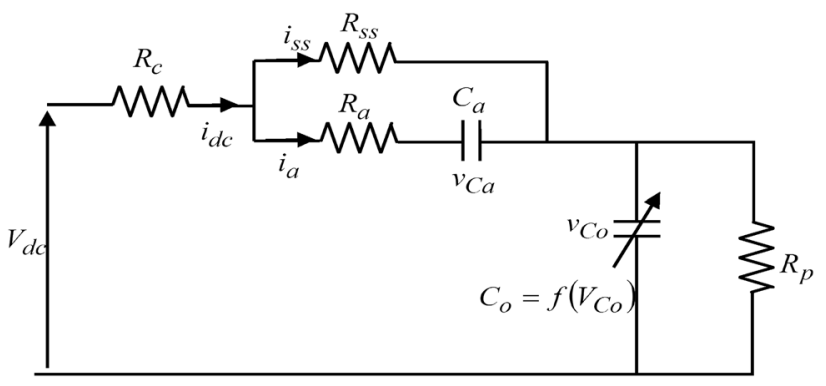

Fig. 4 Equivalent circuit model of a lithium-ion-based super-capacitor 
most attractive feature of super-capacitor is that there are no chemical reactions involved in the process of energy storage and its destocking. The equivalent circuit model of the super-capacitor is shown in Fig. 4. The modeling, calculation of parameters and additional details on the test procedure are presented in [19]. The parameters of super-capacitor are presented in Appendix section. The capacitance $\mathrm{Co}$ is a function of the open circuit voltage:

$\mathrm{Co}=a v_{\mathrm{Co}}^{4}+b v_{\mathrm{Co}}^{3}+c v_{\mathrm{Co}_{\mathrm{O}}}^{2}+d v_{\mathrm{Co}}+e$.

In this model, the self-discharge process is represented by a parallel resistance Rp. However, according to the manufacturer's data, the discharge time from 3 to $2.2 \mathrm{~V}$ is estimated to be 20 years. Laboratory measurements have shown no change in the voltage of an open circuit of a super-capacitor cell during a 3-month period. Sometimes, the parallel resistance in the calculations is legitimate to be neglected. In this circuit model to be used in the design of the D-STATCOM, the parallel resistance is taken as a very high resistance value. Resistor $\mathrm{Rc}$ is a series resistor across the terminals and connected with the rest of the circuit. Based on the equivalent circuit and neglecting $\mathrm{Rp}$, the super-capacitor is modeled as follows:

$\frac{\mathrm{d}}{\mathrm{d} t}\left[\begin{array}{l}v_{\mathrm{Co}} \\ v_{\mathrm{Ca}}\end{array}\right]=\left[\begin{array}{l}0 \\ 0-\frac{1}{C_{\mathrm{a}}\left(R_{\mathrm{ss}}+R_{\mathrm{a}}\right)}\end{array}\right]\left[\begin{array}{l}v_{\mathrm{Co}} \\ v_{\mathrm{Ca}}\end{array}\right]+\left[\begin{array}{c}\frac{1}{C_{\mathrm{o}}} \\ \frac{R_{\mathrm{ss}}}{C_{\mathrm{a}}\left(R_{\mathrm{ss}}+R_{\mathrm{a}}\right)}\end{array}\right]\left[i_{\mathrm{dc}}\right]$

$V_{\mathrm{dc}}=\left[1 \frac{R_{\mathrm{ss}}}{R_{\mathrm{ss}}+R_{\mathrm{a}}}\right]\left[\begin{array}{c}v_{\mathrm{Co}} \\ v_{\mathrm{Ca}}\end{array}\right]+\left[R_{\mathrm{c}}+\frac{R_{\mathrm{a}} R_{\mathrm{ss}}}{R_{\mathrm{ss}}+R_{\mathrm{a}}}\right]\left[i_{\mathrm{dc}}\right]$.

The current ripples through the $\mathrm{AC}$ inductor are allowed to be $5 \%$, and during transient state, current rating of $120 \%$ of steady-state current is taken. The coupling inductance can be calculated by using Eq. (7):

$L_{c}=\frac{\frac{\sqrt{3}}{2} \cdot V_{\mathrm{dc}}}{6 \cdot a \cdot f_{\mathrm{s}} \cdot I_{\mathrm{cr}(p-p)}}$

where $f_{\mathrm{s}}$ is the switching frequency, which is taken as $5 \mathrm{kHz}$.

\section{The modeling of D-STATCOM}

According to this correspondent circuit, the currents and voltages of the D-STATCOM in the Park reference frame are given [20]:

$L_{\mathrm{sh}} \frac{\mathrm{d}}{\mathrm{d} t}\left[\begin{array}{c}i_{\mathrm{q}} \\ i_{\mathrm{d}}\end{array}\right]=\left[\begin{array}{cc}-R_{\mathrm{sh}} & -\omega_{\mathrm{s}} L_{\mathrm{sh}} \\ \omega_{\mathrm{s}} L_{\mathrm{sh}} & -R_{\mathrm{sh}}\end{array}\right]\left[\begin{array}{l}i_{\mathrm{q}} \\ i_{\mathrm{d}}\end{array}\right]+\left[\begin{array}{c}v_{\mathrm{q} \mathrm{PCC}}-v_{\mathrm{q} \mathrm{ST}} \\ v_{\mathrm{d} \mathrm{PCC}}-v_{\mathrm{d} \mathrm{ST}}\end{array}\right]$.
The instantaneous voltages of the network and D-STATCOM are independent, but active and reactive currents are coupled through the reactance of the coupling transformer [21]. In order to design a control approach for monitoring the required value, it is therefore essential to decouple the active and reactive currents.

For the continuous side, the continuous tension is given by:

$V_{\mathrm{dc}}=\frac{1}{C} \int i_{\mathrm{dc}} \mathrm{d} t$

Then, the continuous current is given by:

$i_{\mathrm{dc}}=m\left(i_{\mathrm{q}} \sin (\delta)+i_{\mathrm{d}} \cos (\delta)\right)$.

The ratio $m$ and the angle of phase-shift $\delta$ can be drawn from Fig. 5, which illustrates the vectors of voltages and currents in the Park reference frame. From this figure, one can have the conversion ratio $m$ as follows:

$m=\frac{\sqrt{v_{\mathrm{qST}}^{2}+v_{\mathrm{dST}}^{2}}}{V_{\mathrm{dc}}}$.

The live angle is:

$\delta=\operatorname{tg}^{-1}\left(\frac{v_{\mathrm{qST}}}{v_{\mathrm{dST}}}\right)$.

\section{Control of D-STATCOM by conventional PI controller}

In this section, the control of the D-STATCOM by conventional PI controller is presented in the block diagram shown in Fig. 6. The configuration of this control consists of: two external loops for controlling the voltage of the electrical network, the voltage of the DC bus and the

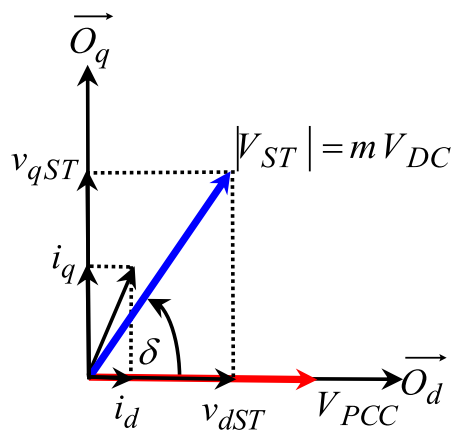

Fig. 5 Vector diagram of D-STATCOM voltages and currents 


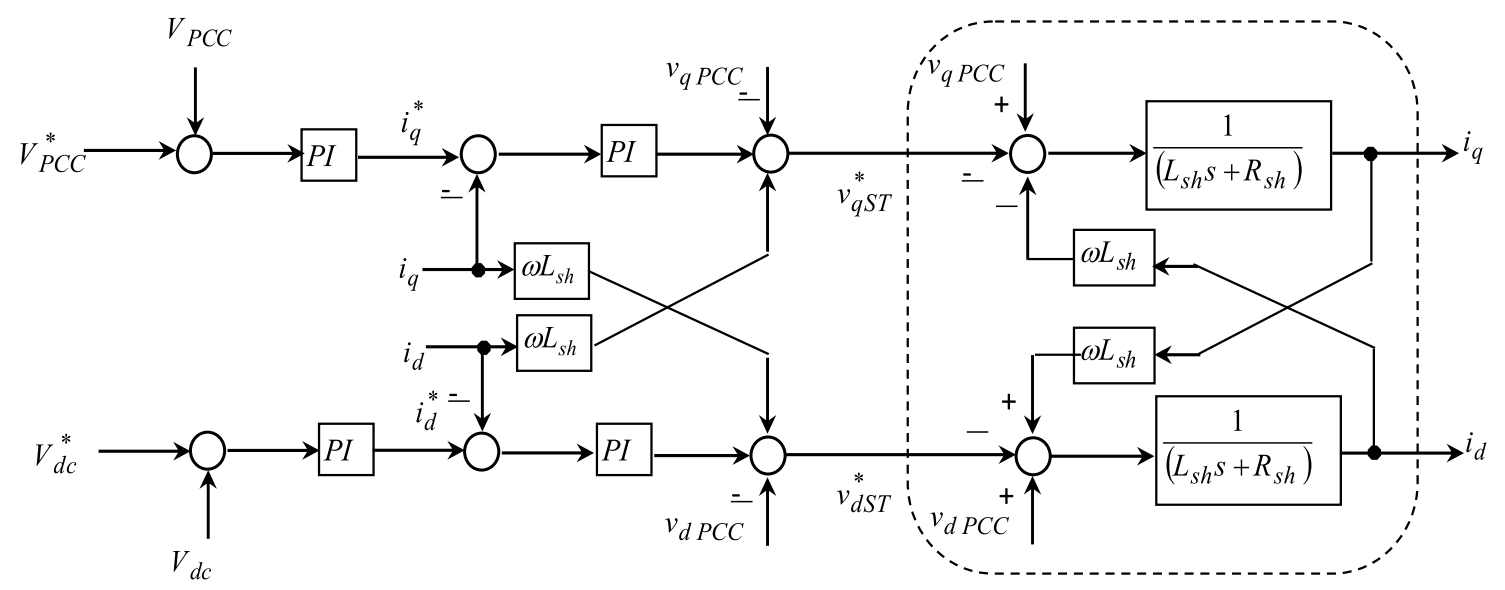

Fig. 6 Block scheme of the D-STATCOM control by conventional PI

other two internal current loops thus control the power exchange between the D-STATCOM and the electrical grid. It can be shown that in the model given by Eq. (4), the two components of currents are coupled.

To achieve effective control, it is necessary to decouple the system, leading directly to a decoupled control configuration by adding coupling terms to the command.

The control configuration used in this section by a conventional $\mathrm{PI}$ controller is to maintain the voltage amplitude at the PCC constant by controlling the amplitude and/ or shifting of the D-STATCOM output voltage. Thus, the current flow between the converter and the network is controlled. The particular problem is often encountered in commands based on this type of conventional PI controllers such as calculating the parameters of the regulators, the delay introduced by the no time in the enslavement loop that can cause system instability if its value becomes too large and the static error. The current transfer function with an open loop PI regulator is expressed by the following equation:

$F_{\mathrm{BO}_{-} i}(s)=\frac{i_{\mathrm{q}}}{i_{\mathrm{q}}^{*}}=\frac{i_{\mathrm{d}}}{i_{\mathrm{d}}^{*}}=\left(K_{p_{-} i}+\frac{K_{i_{-} i}}{s}\right)\left(\frac{1}{L_{\mathrm{sh}} s+R_{\mathrm{sh}}}\right)$.

The closed-loop transfer function is obtained by the following equation:

$F_{\mathrm{BF}_{-} i}(s)=\frac{K_{p_{-} i} s+K_{i_{-} i}}{s^{2}+\left(\frac{R_{\mathrm{sh}}}{L_{\mathrm{sh}}}+K_{p_{-} i}\right) s+K_{i_{-} i}}$

The coefficients of the regulators are calculated with the pole imposition method as explained in [11] and by identification with the canonical function developed by the Ziegler-Nichols tests; these parameters will be given as follows:
$\left\{\begin{array}{l}K_{p_{-} i}=2 \zeta-\frac{R_{\mathrm{sh}}}{L_{\mathrm{sh}}} . \\ K_{i \_i}=w^{2}\end{array}\right.$

According to Eq. (5), the DC bus voltage transfer function with an open loop PI controller is expressed by the following equation:

$F_{\text {BO_dc }}(s)=\frac{V_{\mathrm{dc}}}{V_{\mathrm{dc}}^{*}}=\left(K_{p_{-} \mathrm{dc}}+\frac{K_{i_{-} \mathrm{dc}}}{s}\right)\left(\frac{1}{C_{S}}\right)$.

The closed-loop transfer function is obtained by the following equation:

$F_{\mathrm{BF}_{-} \mathrm{dc}}(s)=\frac{\frac{K_{p \_\mathrm{dc}} s+K_{i-\mathrm{dc}}}{C}}{s^{2}+\frac{K_{p_{\mathrm{d}} \mathrm{dc}}}{C} s+\frac{K_{i-\mathrm{d} c}}{C}}$.

The regulator's coefficients are calculated in the same previous way:

$\left\{\begin{array}{l}K_{p_{-} \mathrm{dc}}=2 \zeta C \\ K_{i_{-} \mathrm{dc}}=w^{2} C\end{array}\right.$.

\section{Control of D-STATCOM by sliding mode}

Unlike the previous conventional PI controller, the SMC has been succeeded in recent years due to its easiness in implementation, simplicity and robustness against system uncertainties and some external disturbances in the industrial process, as well, as its great robustness in relation to modeling errors. This is mainly due to the rapid convergence property of errors in finite time. The principle of the SMC is to drive the system to reach a given surface, designated a sliding surface and to persist there to balance. The D-STATCOM SMC block scheme is shown in Fig. 7. This control approach 
is completed in two stages: convergence to the surface and then sliding along it. The surface is given by the following relationship [22]:

$S(x)=\left(\frac{\partial}{\partial t}+\lambda_{x}\right)^{n-1} e(x)$.

To control active and reactive currents, $n=1$ is taken in Eq. (15), the expression of the sliding surface is modified as shown in (16):

$S_{\mathrm{dq}}=\left[\begin{array}{l}S_{\mathrm{d}}\left(i_{\mathrm{d}}\right) \\ S_{\mathrm{q}}\left(i_{\mathrm{q}}\right)\end{array}\right]=\left[\begin{array}{l}e\left(i_{\mathrm{d}}\right) \\ e\left(i_{\mathrm{q}}\right)\end{array}\right]$,

where $e\left(i_{\mathrm{q}}\right)=i_{\mathrm{q}}^{*}-i_{\mathrm{q}}$ and $e\left(i_{\mathrm{d}}\right)=i_{\mathrm{d}}^{*}-i_{\mathrm{d}}$; then, their derivatives are:

$\dot{S}_{\mathrm{dq}}=\left[\begin{array}{l}\dot{S}_{\mathrm{d}}\left(i_{\mathrm{d}}\right) \\ \dot{S}_{\mathrm{q}}\left(i_{\mathrm{q}}\right)\end{array}\right]=\left[\begin{array}{l}\dot{i}_{\mathrm{d}}^{*}-\dot{i}_{\mathrm{d}} \\ \dot{i}_{\mathrm{q}}^{*}-\dot{i}_{\mathrm{q}}\end{array}\right]$.

By substituting the currents expression from (4) to (17), the derivatives of sliding surfaces become:

$\dot{S}_{\mathrm{dq}}=F_{\mathrm{ST}}+D_{\mathrm{ST}} V_{\mathrm{ST}}$

where

$F_{\mathrm{ST}}=\left[\begin{array}{l}\dot{i}_{\mathrm{d}}^{*}+\frac{R_{\mathrm{sh}}}{L_{\mathrm{sh}}} i_{d}-\omega_{\mathrm{s}} i_{\mathrm{q}}-\frac{v_{\mathrm{dPCC}}}{L_{\mathrm{sh}}} \\ \dot{i}_{\mathrm{q}}^{*}+\omega_{\mathrm{s}} i_{\mathrm{d}}+\frac{R_{\mathrm{sh}}}{L_{\mathrm{sh}}} i_{\mathrm{q}}-\frac{v_{\mathrm{q} P C}}{L_{\mathrm{sh}}}\end{array}\right]$
$D_{\mathrm{ST}}=\frac{1}{L_{\mathrm{sh}}}, \overline{V_{\mathrm{ST}}}=\left[\begin{array}{ll}v_{\mathrm{dST}} & v_{\mathrm{q} S \mathrm{ST}}\end{array}\right]^{\top}$.

Lyapunov's stability theory is utilized here to authenticate about the convergence of zero-slide surfaces, meeting the subsequent situation:

$\dot{V}=S^{\top} \dot{S}<0$.

From Eq. (4), the voltage of the applied D-STATCOM is acquired by using following control law:

$\overline{V_{\mathrm{ST}}}=\left[\begin{array}{c}v_{\mathrm{dST}} \\ v_{\mathrm{qST}}\end{array}\right]=\left[\begin{array}{l}v_{\mathrm{dST}, \mathrm{eq}}+v_{\mathrm{dST}, n} \\ v_{\mathrm{qST}, \text { eq }}+v_{\mathrm{qST}, n}\end{array}\right]$,

where $\left[v_{\mathrm{dST}, \text { eq }}, v_{\mathrm{qST}, \text { eq }}\right]^{\top}$ the equivalent is command $\left[v_{\mathrm{dST}, n}, v_{\mathrm{qST}, n}\right]$ and is the part of the discontinuous control. Taking into account the corresponding part and switching, the Eq. (22) becomes Eq. (23). The proposed SMC strategy is presented in Fig. 4.

$\overline{V_{\mathrm{ST}}}=\left[\begin{array}{c}v_{\mathrm{dST}} \\ v_{\mathrm{qST}}\end{array}\right]=-D_{\mathrm{ST}}^{-1} F_{\mathrm{ST}}-D_{\mathrm{ST}}^{-1}\left[\begin{array}{cc}a_{i_{\mathrm{d}}} & 0 \\ 0 & a_{i_{\mathrm{q}}}\end{array}\right]\left[\begin{array}{l}\operatorname{sign}\left(S_{\mathrm{d}}\left(i_{\mathrm{d}}\right)\right) \\ \operatorname{sign}\left(S_{\mathrm{q}}\left(i_{\mathrm{q}}\right)\right)\end{array}\right]$,

where $a_{i_{d}}>0$ and $a_{i_{q}}>0$, The equivalent order terms are obtained by leaving $\dot{S}_{\mathrm{dq}}=0$

$\left[\begin{array}{c}v_{\mathrm{dST}, \mathrm{eq}} \\ v_{\mathrm{qST}, \mathrm{eq}}\end{array}\right]=-D_{\mathrm{ST}}^{-1} F_{\mathrm{ST}}=\left[\begin{array}{l}-L_{\mathrm{sh}} i_{\mathrm{d}}^{*}-R_{\mathrm{sh}} i_{\mathrm{d}}+\omega_{\mathrm{s}} L_{\mathrm{sh}} i_{\mathrm{q}}+v_{\mathrm{d} \mathrm{PCC}} \\ -L_{\mathrm{sh}} i_{\mathrm{q}}^{*}-\omega_{\mathrm{s}} L_{\mathrm{sh}} i_{\mathrm{d}}-R_{\mathrm{sh}} i_{\mathrm{q}}+v_{\mathrm{q} \mathrm{PCC}}\end{array}\right]$.

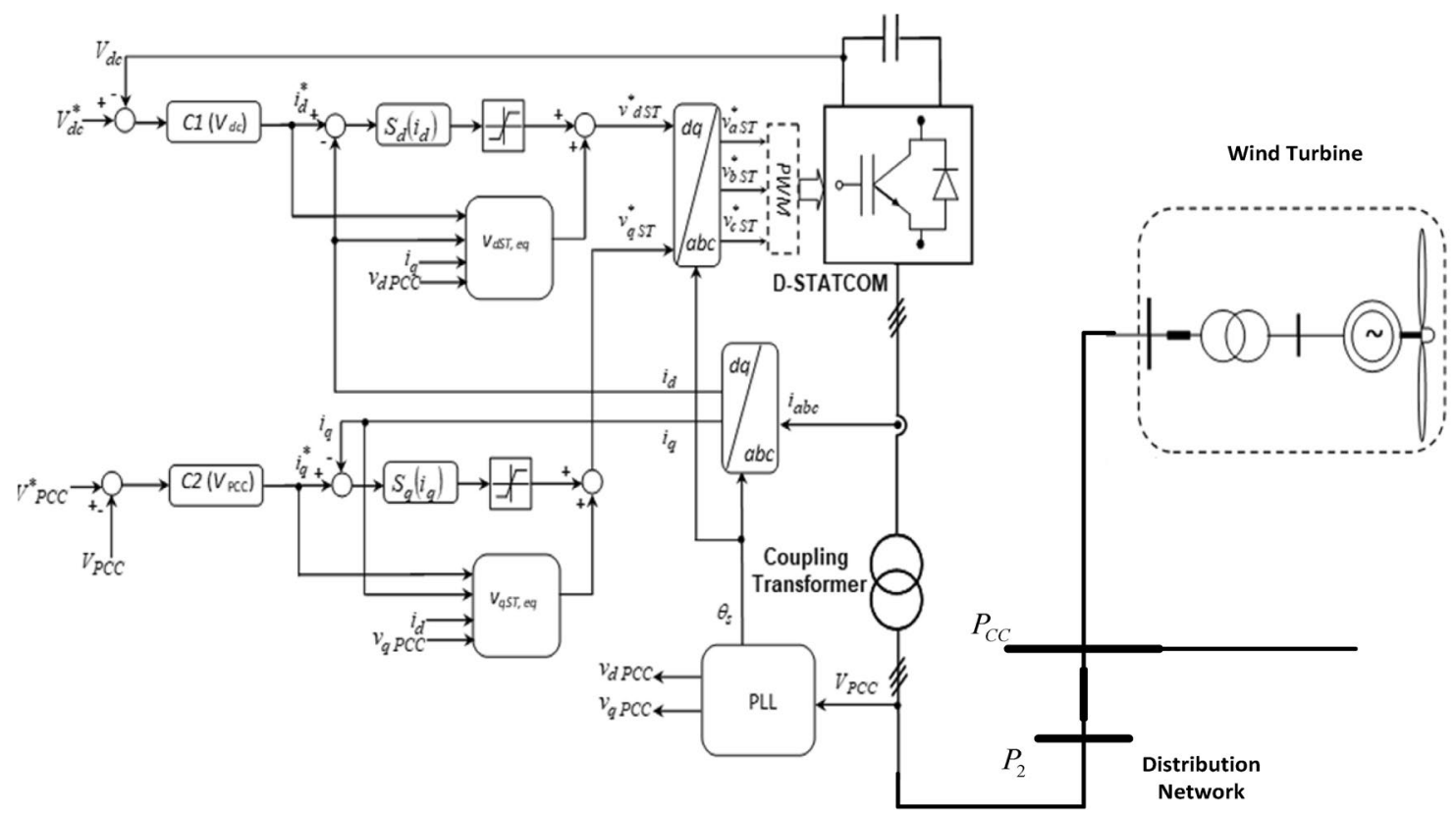

Fig. 7 D-STATCOM SMC block scheme 


\section{Simulation result and discussion}

In this simulation part under the Matlab/Simulink environment, two control configurations will be tested to show the behavior of the D-STATCOM linked with the power distribution grid. The two types of control configurations are as follows:

- The D-STATCOM is regulated by conventional PI

- The D-STATCOM is regulated by SMC

For the practical execution, the simulations are carried out by a fixed step of $0.5 \mathrm{~ms}$. To test the dynamic behavior of the system studied with these two types of controllers, defects in the electrical distribution network are involved in simulation. The two modes of operation that are considered either fully capacitive by a voltage drop defect or inductive by a voltage swell defect occur in the electrical distribution grid as presented in Fig. 8. By keeping the similar value of PCC reference voltage at $1 \mathrm{pu}$, at the moment $t=0.5 \mathrm{~s}$, a voltage drop is applied in the PCC, and then, at moment $t=1.5 \mathrm{~s}$ a voltage swell is also applied. The simulation results for the D-STATCOM control configuration by a conventional $\mathrm{PI}$ are shown in Fig. 8, while the voltage at PCC with D-STATCOM compensation, i.e., by SMC is presented with the help of Fig. 9.

Figure 10a shows that the caused voltage defects are automatically damped by the intervention of D-STATCOM. Figure $10 \mathrm{~b}$ shows that by using sliding control configuration, the voltage drops caused at the moment $t-0.5 \mathrm{~s}$ is spontaneously compensated by the interference of D-STATCOM with a reduced error and less oscillations compared to control loop based on conventional PI controller. The only difference is the thickness of the voltage response obtained by the classical controller compared to

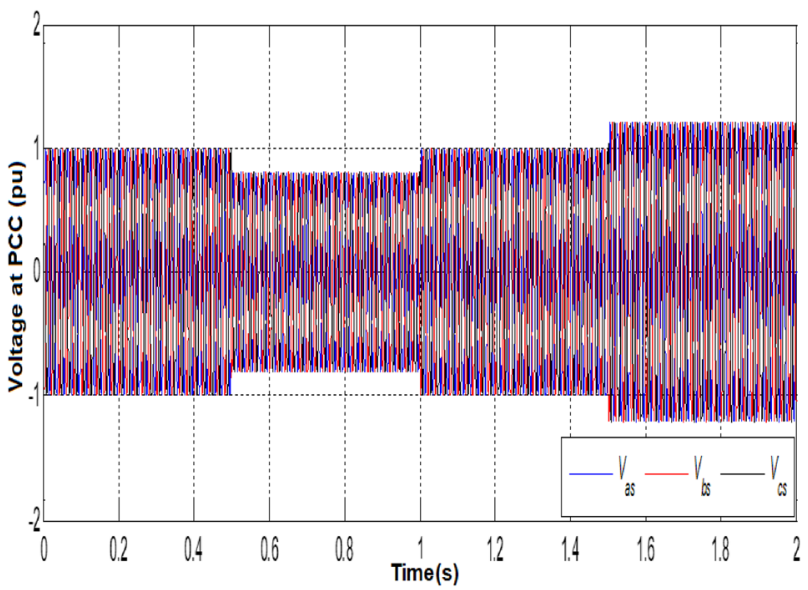

Fig. 8 Voltage at PCC without compensation from D-STATCOM

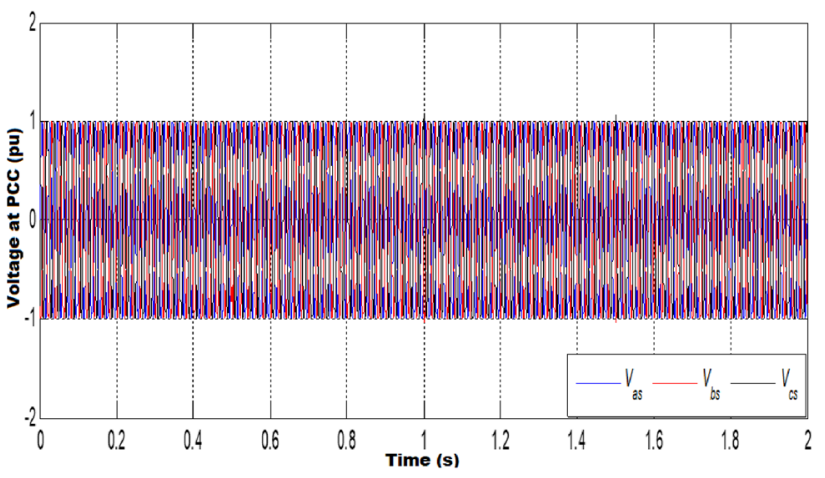

Fig. 9 Voltage at PCC with D-STATCOM compensation

that obtained by the proposed controller SMC. The thickness is high-frequency ripples that are corrected by the proposed controller. These oscillations have an impact on the current responses because the voltage is an outer loop feeding the current loop which is considered as an inner loop.

The following figures illustrate the dynamic responses of the reactive current and the active current of the D-STATCOM, respectively.

According to Fig. $11 \mathrm{a}$, b, the reactive current is positive by $0.5 \mathrm{~s}$ to the $1 \mathrm{~s}$, which shows that the D-STATCOM is in capacitive mode, i.e., it generates reactive power to damp
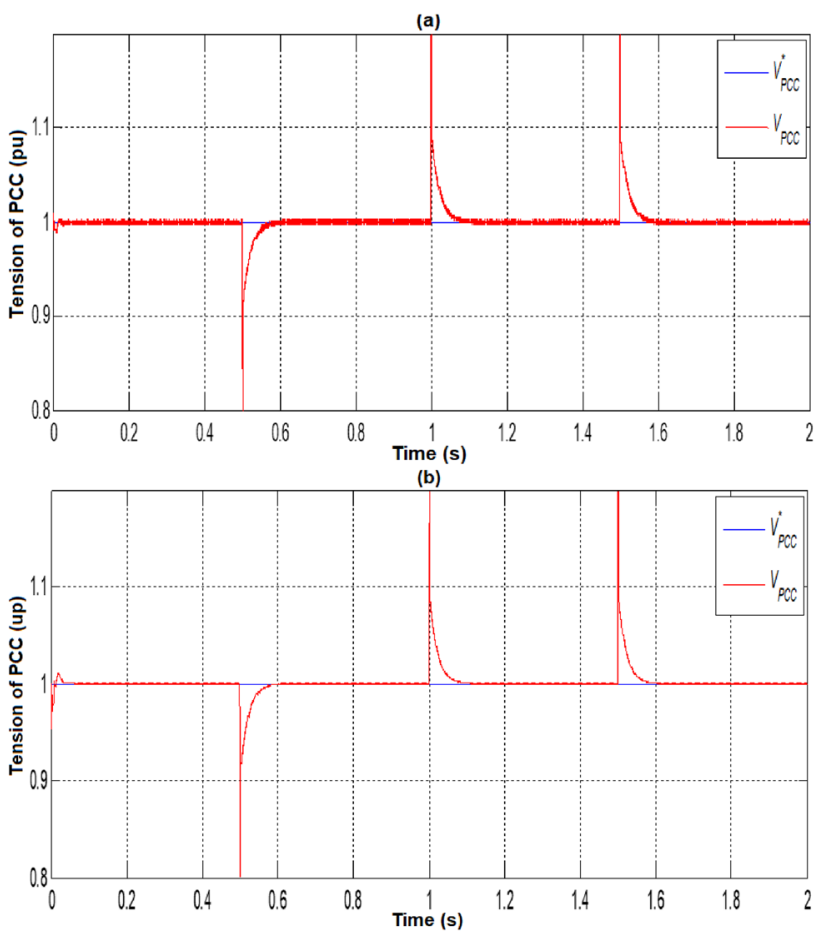

Fig. 10 Magnitudes of the voltage in the PCC: a D-STATCOM with a conventional PI regulator, b D-STATCOM with a SMC 

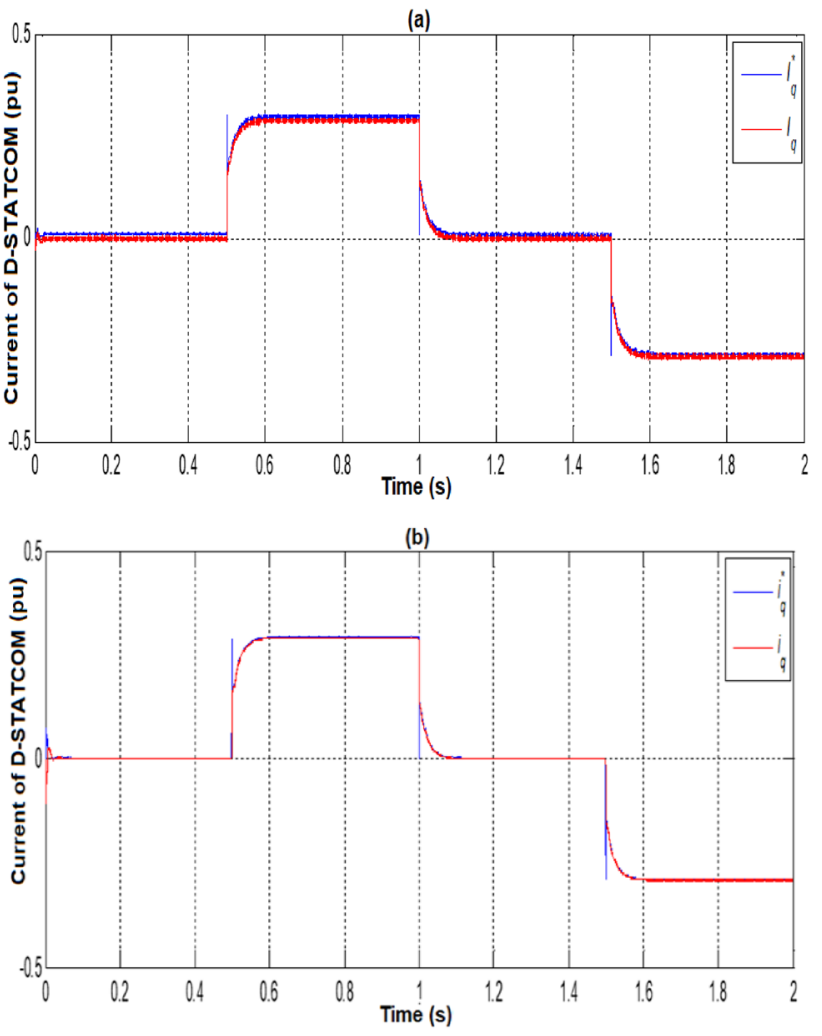

Fig. 11 Dynamic responses of reactive currents: a D-STATCOM with a conventional PI regulator, b D-STATCOM with a SMC

the voltage drop in the PCC. Then, the reactive current becomes negative from 1.5 to $2 \mathrm{~s}$ which shows that the D-STATCOM is in inductive mode that is it absorbs reactive power for the damping of the swell in the electrical grid. In addition, the static error in the d-STATCOM's response to the sliding mode is reduced compared to a D-STATCOM operating through a conventional PI regulator.

Figure 12a shows that the active current for a D-STATCOM with a conventional $\mathrm{PI}$ controller is oscillating which can also influence the maintenance of continuous bus voltage and the compensation of active losses in the system's equivalent resistance. However, Fig. $12 \mathrm{~b}$ shows the active current for D-STATCOM operation with SMC, a zero value of the static error corresponding to the maintenance of the continuous bus voltage.

Figure 13 shows the dynamic responses of the active and reactive powers of the D-STATCOM.

Figure 13a, b illustrates the D-STATCOM's function from an inductive mode from 0.5 to $1 \mathrm{~s}$, in capacitive mode from 1.5 to $2 \mathrm{~s}$, delivering the amounts of reactive power
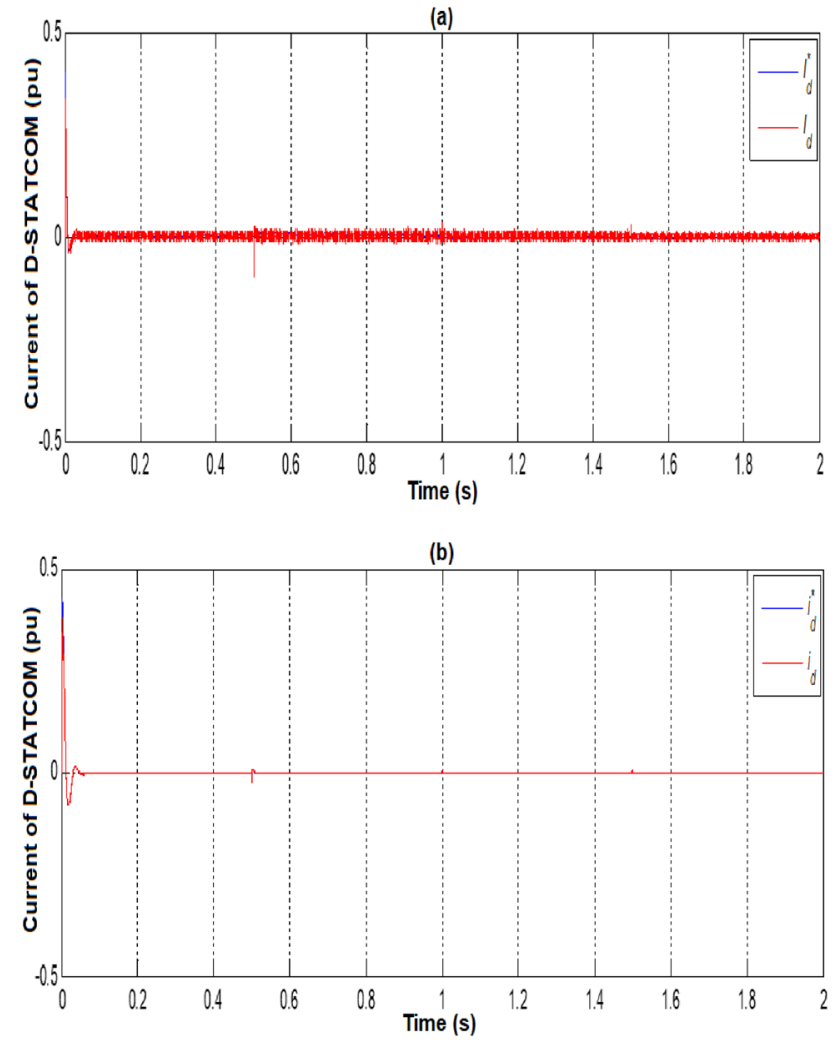

Fig. 12 Dynamic active current responses: a D-STATCOM with a conventional PI regulator, b D-STATCOM with a SMC

needed to maintain voltage in a stable power distribution network. In addition, by comparing the reactive powers provided using the sliding mode control, an error reduction is achieved with less oscillation compared to the system using the control by a conventional PI.

The currents injected by D-STATCOM to the electrical distribution network using both types of controls as well as their harmonic spectrum are shown in Fig. 14.

From Fig. $14 a$, b, we note that during the $(0-0.5)$ second and (1-1.5) second time period, the D-STATCOM device with both types of controls is in balance condition (floating mode, i.e., out of service). The network voltage is identical to the D-STATCOM voltage, no current circulates during the transition between different modes of operation (capacitive and inductive). On the other hand, it can be observed that in transient, the amplitude of oscillations is very close to zero for the proper working of D-STATCOM with SMC and no current 


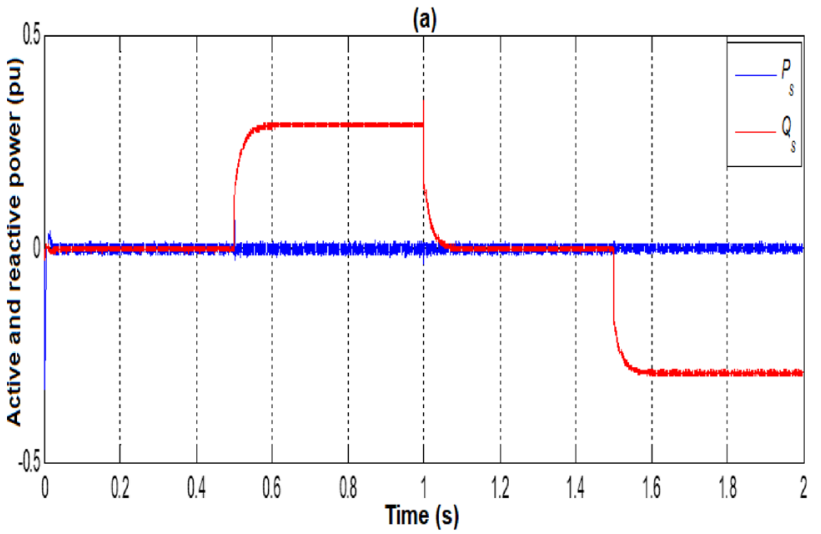

(b)

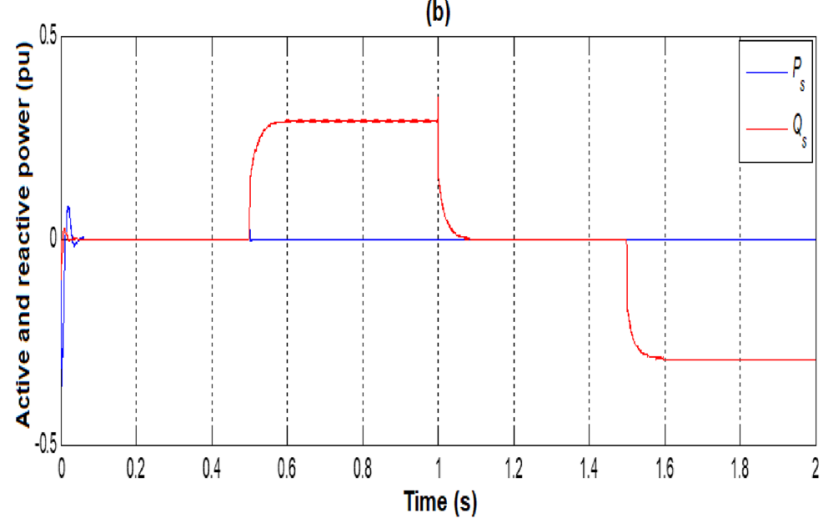

Fig. 13 Active and reactive power injected by: a D-STATCOM with a conventional PI controller, b D-STATCOM with a SMC

exchanged between this device and the electrical distribution network.

Figure 15 shows the current harmonics injected by the D-STATCOM. From Fig. 15a, b, it can be noted that with the use of the control by sliding mode, the harmonics in these injected currents are attenuated compared to the previous command based on a conventional PI controller. According to Fig. 15, THD spectrum for D-STATCOM with PI controller is $9.45 \%$, while the THD spectrum for D-STATCOM with SMC is $2.65 \%$. Hence, the proposed controller is showing better performance in term of THD reduction.

Figure 16 represents the voltage in the D-STATCOM continuous bus. Initially, the capacitor of the D-STATCOM is charged and the voltage at these terminals is $1.0 \mathrm{pu}$. According to Fig. 16, it is very clear that the SMC has proved its efficiency in maintaining the $\mathrm{DC}$ bus voltage at
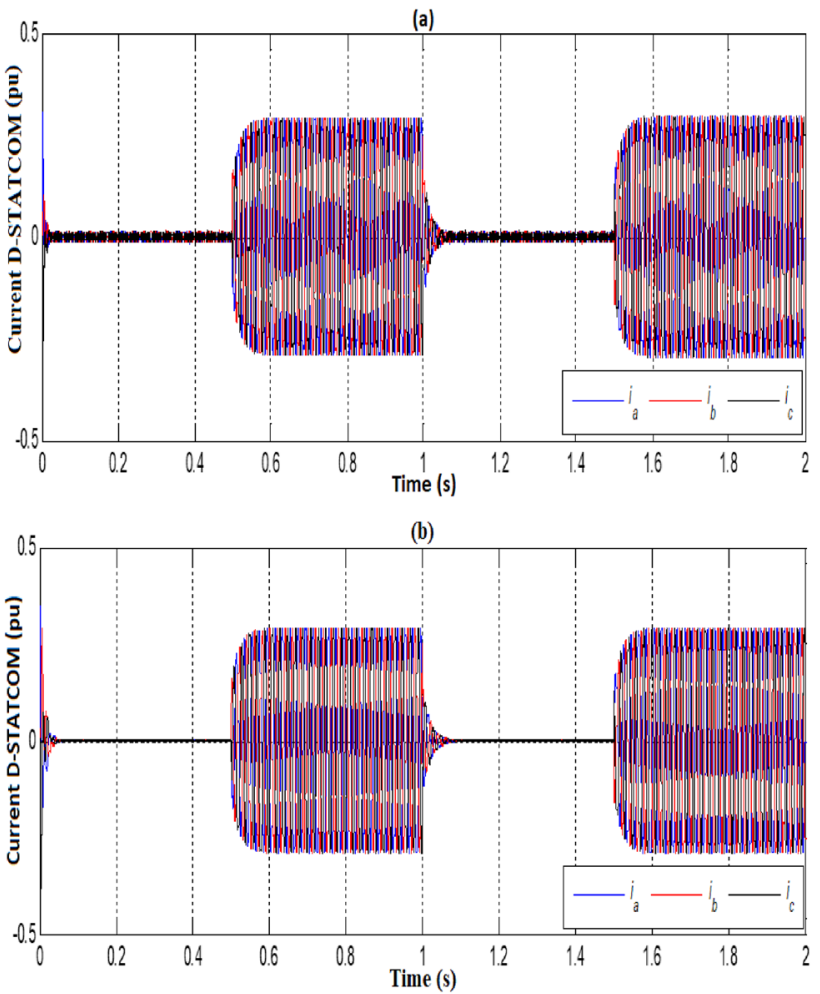

Fig. 14 Current of the D-STATCOM with: a conventional PI control, b SMC

constant value $V_{\mathrm{dc}}=1.0$ pu across the capacitor, compared to the control by a conventional PI controller that showed some small ripples.

Moreover, the comparison of SMC and conventional PI controller is displayed in Table 1. This performance evaluation is based on following factors, such as total harmonic distortion (THD), time response, error tracking and oscillations. Among both controllers, SMC gives better performance as compared to conventional PI controller.

\section{Conclusion}

This article perceived the introduction of a new concept on control strategy that is needed to increase the operational efficiency of D-STATCOM. In the simulation results, a 

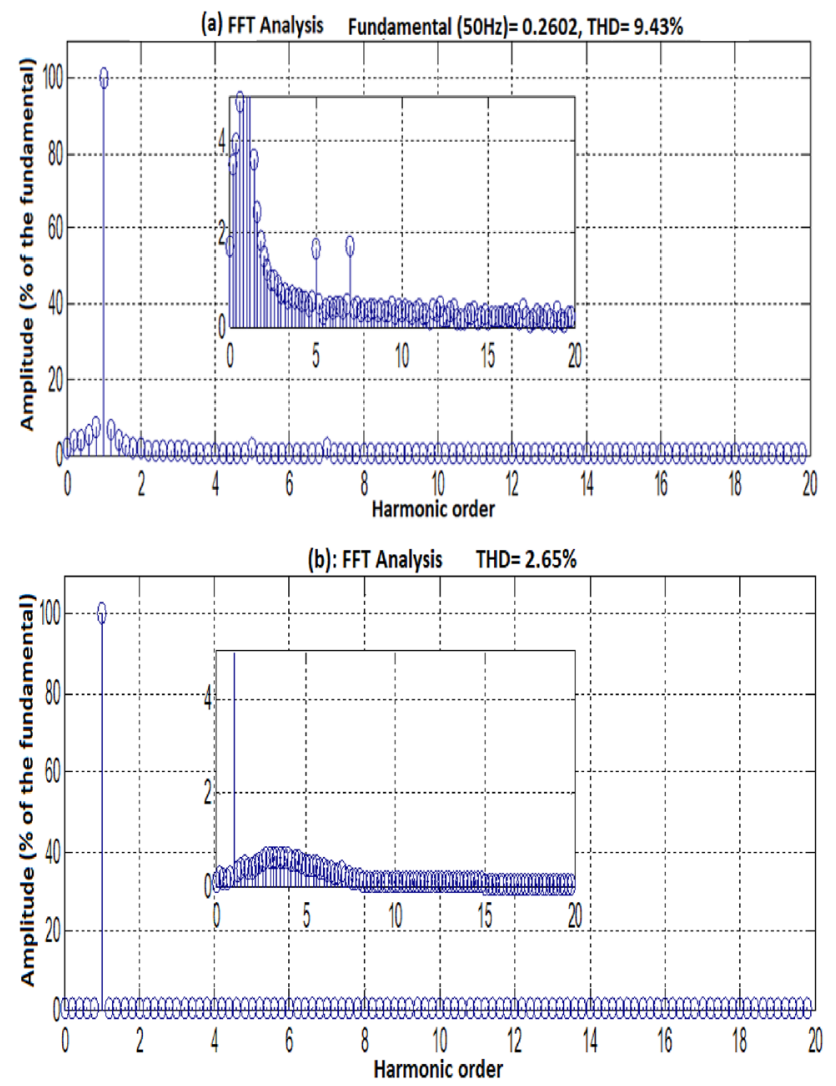

Fig. 15 Current harmonic spectrum: a D-STATCOM with a conventional PI regulator, b D-STATCOM with SMC

reduction in oscillation is greatly shown by the configuration of the control approach by SMC compared to the results of the other controller based on a conventional PI. The static error also reduced. In particular, the currents coming out of the transformer in the PCC turn out to be stable with less harmonics.

Therefore, the proposed control scheme is capable of offering good performance to the distribution electrical grid by reducing the current harmonics and increasing the power quality in the electrical grid. This also corresponds to the accepted value of total harmonic distortion, i.e., THD (2.65-5)\% according to the IEEE Standard 519-1992.

Acknowledgements This work was supported in part by the National Key Research and Development Program of China under Grants (Nos. 2018AAA0101502 and 2018YFB1004800), National Natural Science Foundation of China under Grants U1811463, U1909204, 61773381 and 61702519.

\section{Compliance with ethical standards}

Conflict of interest On behalf of all authors, the corresponding author states that there is no conflict of interest.
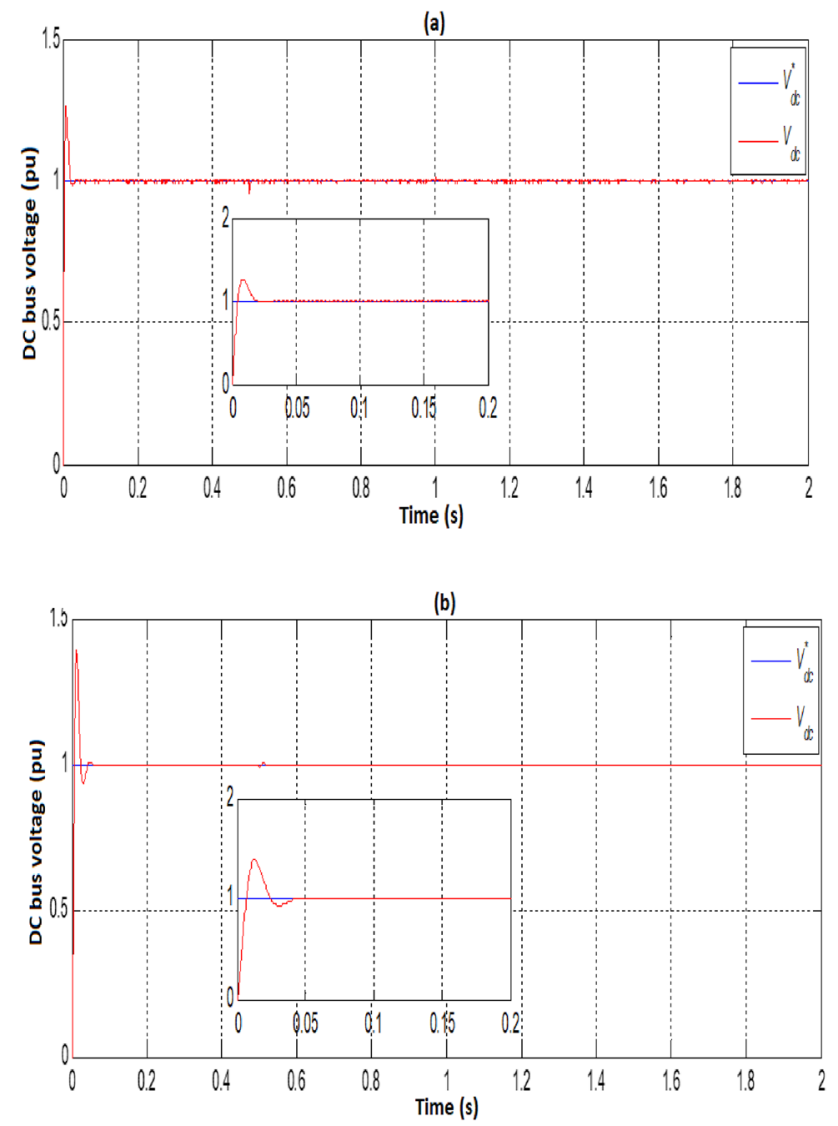

Fig. 16 Dynamic response to DC bus voltage: a D-STATCOM with a conventional PI controller, b D-STATCOM with SMC

Table 1 Performance comparison of SMC and PI controller

\begin{tabular}{lll}
\hline Parameters & PI controller & SMC \\
\hline THD & $9.45 \%$ & $2.65 \%$ \\
Time response & $0.027 \mathrm{~s}$ & $0.052 \mathrm{~s}$ \\
Reference tracking error & $6.7 \%$ & $0.83 \%$ \\
Oscillations & $2.0 \%$ & $0.5 \%$ \\
\hline
\end{tabular}

\section{Appendix}

In this session, the following tables are added in appendix. The parameters of super-capacitor are presented in Table 2 and described as follows.

Furthermore, the simulations are studied with a D-STATCOM connected to electrical grid with the parameters that are described as follows with the help of Table 3. 
Table 2 Parameters of super-capacitor

\begin{tabular}{llrl}
\hline Parameters & & Values \\
\hline Resistance $R_{\mathrm{c}}$ in series & & & $0.01 \Omega$ \\
Capacitor $C_{\mathrm{a}}$ & & $30.6 \mathrm{mF}$ \\
Resistance $R_{\mathrm{a}}$ in series & & $C$ & $79.9 \mathrm{~m} \Omega$ \\
Resistance $R_{\mathrm{ss}}$ in series & & $5.34 \mathrm{~m} \Omega$ \\
\hline$A$ & $B$ & & $D$ \\
\hline Coefficient of polynomial $C_{0}$ & & $45,480.90$ & $-73,516.72$ \\
-703.39 & 9359.27 & $96,048.08$ & \\
\hline
\end{tabular}

Table 3 Parameters for D-STATCOM connected to electrical grid

\begin{tabular}{ll}
\hline Parameters & Values \\
\hline Transformer rated voltage & $2.5 / 30 \mathrm{kV}$ \\
Rated frequency & $50 \mathrm{~Hz}$ \\
Apparent rated power & $3-15 \mathrm{MVA}$ \\
Resistance & $0.22 / 30 \mathrm{pu}$ \\
Inductance & $0.22 \mathrm{pu}$ \\
Continuous DC tension & $4000 \mathrm{~V}$ \\
\hline
\end{tabular}

\section{References}

1. Bollen MHJ (1999) Understanding power quality problems: voltage sags and interruptions. IEEE Press, New York

2. Hingorani N (1995) Introducing custom power. IEEE Spectr 32(6):41-48

3. Gosh A, Ledwich G (2002) Power quality enhancement using custom power devices. Kluwer, Norwell

4. Ananth DVN, Kumar GN (2015) Fault ride-through enhancement using an enhanced field-oriented control technique for converters of grid connected DFIG and STATCOM for different types of faults. ISA Trans 62:2-18

5. Mancer N, Mahdad B, Srairi K (2012) Multi objective optimal reactive power flow based STATCOM using three variants of PSO. Int J Energy Eng 2:1-7

6. Chebabhi A, Fellah MK, Kessal A, Benkhoris MF (2016) Four leg D-STATCOM based on synchronous reference frame theory with enhanced phase locked loop for compensating a four wire distribution network under unbalanced PCC voltages and loads. J Power Technol 96:0957

7. Xi Z, Parkhideh B, Bhattacharya S (2008) Improving distribution system performance with integrated STATCOM and supercapacitor energy storage system. In: Power electronics specialists conference, 2008 IEEE power electronics specialists conference, pp 1390-1395

8. Kerrouche K, Mezouar A, Boumedien L (2013) A simple and efficient maximized power control of DFIG variable speed wind turbine. In: Systems and control (ICSC), 2013 3rd international conference, pp 894-899

9. Kerrouche KD-E, Mezouar A, Boumediene L, Van Den Bossche A (2016) Modeling and Lyapunov-designed based on adaptive gain sliding mode control for wind turbines. J Power Technol 96(2):124-136
10. Kerrouche KD-E, Mezouar A, Boumediene L, Van Den Bossche A (2016) Speed sensor-less and robust power control of grid-connected wind-turbine-driven doubly fed induction generators based on flux orientation. Mediterr J Meas Control 12(3):606-618

11. Kerrouche KDE, Mezouar A, Boumediene L, Van Den Bossche A (2016) A comprehensive review of LVRT capability and sliding mode control of grid-connected wind-turbine-driven doubly fed induction generator. Autom - J Control Meas Electron Comput Commun 60:922-935

12. Li S, Xu L, Haskew A (2013) Control of VSC-based STATCOM using conventional and direct-current vector control strategies. Electr Power Energy Syst 45:175-186

13. Chebabhi A, Fellah MK, Kessal A, Benkhoris MF (2016) Four leg D-STATCOM based on synchronous reference frame theory with enhanced phase locked loop for compensating a four wire distribution network under unbalanced PCC voltages and loads. J Power Technol 96:15

14. Döşoğlu M, Arsoy AB, Güvenç U (2017) Application of STATCOM super capacitor for low-voltage ride-through capability in DFIG based wind farm. Neural Comput Appl 28(9):2665-2674

15. Zhang X-P, Rehtanz C, Pal B (2012) Flexible AC transmission systems: modelling and control. Springer, Berlin

16. Mokhtari M, Zouggar S, Elhafyani ML, Ouchbel T, Benzaouia S, Fannakh M (2018) Design, simulation and performance analysis of voltage regulator based on STATCOM for asynchronous wind turbine. In: International conference on electronic engineering and renewable energy. Springer, Singapore, pp 498-509

17. Movahedi A, Niasar AH, Gharehpetian GB (2019) Designing SSSC, TCSC, and STATCOM controllers using AVURPSO, GSA, and GA for transient stability improvement of a multi-machine power system with PV and wind farms. Int J Electr Power Energy Syst 106:455-466

18. Zhang G, Hu W, Cao D, Yi J, Huang Q, Liu Z, Blaabjerg F (2020) A data-driven approach for designing STATCOM additional damping controller for wind farms. Int J Electr Power Energy Syst 117:105620

19. Manla E, Mandic G, Nasiri A (2011) Testing and modeling of lithium-ion ultra-capacitors. In: IEEE energy conversion congress and exposition (ECCE), pp 2957-2962

20. Wessels C, Hoffmann N, Molinas M, Fuchs FW (2013) StatCom control at wind farms with fixed-speed induction generators under asymmetrical grid faults. IEEE Trans Ind Electron 60(7):2864-2873

21. Draou A, Benghanen M, Tahri A (2001) Multilevel converters and VAR compensation. In: Rashid MH (ed) Power electronics handbook. Academic Press, New York, pp 615-622

22. Slotine J-JE, Li W (1991) Applied nonlinear control, vol 199. Prentice-Hall, Englewood Cliffs

Publisher's Note Springer Nature remains neutral with regard to jurisdictional claims in published maps and institutional affiliations. 